administrators who are dedicated to the transformation of the system. While successes are fragile, they just might succeed in sustaining, expanding, and institutionalizing these changes. That is the challenge for 20I4-20I5. We think the chances of continued success are good.

\section{The Challenges of Develop- ing an Autonomous Higher Education System in Afghanistan}

\section{Joseph B. Berger And HanNI S. THOMA}

Joseph B. Berger is professor at the University of Massachusetts Amherst College of Education. E-mail: jbberger@educ.umass.edu. Hanni S. Thoma is a graduate assistant at the University of Massachusetts Amherst. E-mail hthoma@educ.umass.edu.

$T^{t}$ is well documented that until 200I higher education in 1 Afghanistan had been severely impacted by the effects of a nearly three-decade long period of violent conflict. However, since 200I there have been ongoing efforts to reestablish high quality tertiary education capable of meeting the rapidly growing demands of the country's emerging democracy, with a developing economy and a bourgeoning cadre of young men and women thirsty for higher education. Demand for higher education has increased dramatically in Afghanistan over the past decade, with the number of students growing from approximately 6,000 in $200 \mathrm{I}$ to almost 100,000 in 2012, and over 300,000 projected by 2020 in the public higher education system alone, with an additional 100,000 students expected to be enrolled in private institutions as of 2015. Public universities continue to be the dominant higher education institutions in Afghanistan and remain the first choice for all qualified studentsgiven that access is free to all students who qualify and that the public institutions are viewed as the legitimately prestigious academic institutions in the Afghan society. Private institutions enjoy significant autonomy, but most of these institutions are quite small, not highly regarded, and fail to meet minimal standards for academic quality. Thus, a more autonomous public system and greater regulation of private institutions are essential conditions for the further development of a high-quality higher education system in Afghanistan.

\section{InSTITUTIONAL AUTONOMY}

The public higher education system in Afghanistan is one of the most highly centralized systems in the world, and until two years ago the Ministry of Higher Education (MoHE) controlled virtually every aspect of decisionmaking for individual campuses. With support from the international donor community, the MoHE made significant strides towards improving the scope and quality of higher education in Afghanistan, driven by this highly centralized approach. But in order to further support campus growth and development, in 2009 the MoHE initiated a National Higher Education Strategic Plan (NHESP) that called for, among other priorities, increased autonomy for public postsecondary institutions.

Until recently, there has been no clear strategy for how to move forward with increased autonomy on individual public campuses. A great deal of effort has been invested in the improvement of policy frameworks that provide a system-wide framework for increased autonomy, which is an important foundation for then moving to the development and implementation of (a) procedures and infrastructure for implementing policy and (b) enhanced human capacity in the ministry and the constituent university campuses. Recent efforts have been implemented to improve the capacity of Afghan universities to be more autonomous in three strategic areas: academic, administrative, and financial.

Academic autonomy focuses on increasing the role of

faculty and administrative leaders in an improving quality assurance system, based on twelve national standards that are evaluated through self-studies and peer reviews within the campuses. This shift increasingly moves the role of the MoHE from rigid academic control to coordination.

Administrative autonomy is focused on capacity development activities in six critical areas required for the Public Financial Management Risk Assessment (PFMRA). These areas include organizational leadership, internal auditing, 
finance and accounting, human resources, procurement, and information technology. The MoHE is focusing on building parallel capacity in the ministry and each of the major public universities in order to pilot increased administrative autonomy across the essential administrative functions.

Financial autonomy is closely linked to some areas of administrative autonomy, but the current focus is on changing the higher education finance law in Afghanistan that mandates free tuition and prohibits the retention of any funds earned by a university. This legal arrangement does little to incentivize institutions to develop innovative programs; rather such efforts are typically perceived as a superfluous drain on faculty and institutional resources. The inability to generate and manage funds has been particularly problematic given the lack of resources of the Afghan government to adequately fund higher education. In fact, 80 percent of the national budget comes from the international donor community, a very limited and tenuous resource base at best. Four institutions are piloting limited financial autonomy and there has been a push to change the law, but the process is highly complex, involving reviews by multiple government agencies and committees.

Conversely, private higher education institutions have been extremely autonomous as they are almost wholly unregulated. However, MoHE began to address this issue with the first ever review of private institutions in 2013-20I4 in which almost all of the private institutions were found to be of dubious quality. Unfortunately, MoHE lacks the political and financial resources to enforce any types of standards in the largely unregulated and historically underdeveloped private sector.

The formal higher education system is just beginning to define the roles and responsibilities of four types of organizational units-MoHE, the Commission on Quality Assurance, public universities, and private institutions. First, the MoHE is firmly entrenched as a central administrative unit comprised of various subunits (divisions, directorates, and departments) that provides highly centralized governance and coordination of all higher education activity in the country. Second, semiautonomous national coordinating committees and commissions, such as the national Commission on Quality Assurance, are just beginning to emerge; and the development of these bodies will be essential for coordinating and aligning policies, procedures, and practice throughout a more autonomous higher education system. Third, public institutions remain semiautonomous academic units (each of whom have subunits in the form of faculties and departments) that are responsible for the direct delivery of higher education throughout the country, but still have limited autonomy to make strategic and operational decisions related to academic, administrative, and financial functions. Fourth, private institutions are highly autonomous and MoHE is considering ways to bring them in under the emerging quality assurance system.

\section{CONCLUSION}

Higher education, like most aspects of Afghan life, has made significant progress in the last decade. Policy frameworks and procedures are being implemented to increase institutional autonomy in the public sector; however, it will take several more years before individual leaders and academic staff have the capacity to take full advantage of the opportunities for increased autonomy. At the same time, Afghanistan will struggle to manage the lack of control within the private sector. It is clear that the discrepancy in quality, cost, and autonomy between the public and private sectors of higher education presents another layer of complexity that must be addressed in the near future as the private sector continues to grow in size and potential importance. The higher education system has been firmly reestablished, and these changes will slowly contribute to improving the quality and relevance of an accessible and sustainable higher education system that can more capably contribute to the myriad of challenges to loom as Afghanistan increasingly charts its own course as a sovereign state.

\section{Institutionalization of Community Engagement at African Universities}

\section{Henry Mugabi}

Henry Mugabi is researcher, Higher Education Group, University of Tampere, Finland. E-mail: Henry.Mugabi@uta.fi.

lthough the earliest universities in Europe began as Ateaching-only institutions, many have expanded to embrace teaching, research, and community outreach and engagement. African universities are also expected to teach, conduct research, and serve society. At the I962 UNESCO conference on the "Development of Higher Education in Africa," African higher education institutions were urged to be in constant touch with society and to adapt their teaching and research activities toward African problems. In fact, a number of African universities-such as, Nelson Mandela Metropolitan University, Makerere University, University of Botswana, University of KwaZulu-Natal, University of Mauritius, University of Ghana, and University 